\title{
Effects of Wheat streak mosaic virus on Root Development and Water-Use Efficiency of Hard Red Winter Wheat
}

\author{
J. A. Price and F. Workneh, Texas AgriLife Research, Amarillo 79106; S. R. Evett, United States Department of \\ Agriculture-Agricultural Research Service Conservation \& Production Research Laboratory, Bushland, TX 79012;
} and D. C. Jones, J. Arthur, and C. M. Rush, Texas AgriLife Research, Amarillo

\begin{abstract}
Price, J. A., Workneh, F., Evett, S. R., Jones, D. C., Arthur, J., and Rush, C. M. 2010. Effects of Wheat streak mosaic virus on root development and water-use efficiency of hard red winter wheat. Plant Dis. 94:766-770.

Greenhouse and field studies were conducted to determine the effects of Wheat streak mosaic virus (WSMV), a member of the family Potyviridae, on root development and water-use efficiency (WUE) of two hard red winter wheat (Triticum aestivum) cultivars, one susceptible and one resistant to WSMV. In the greenhouse studies, wheat cultivars were grown under three water regimes of 30,60, and $80 \%$ soil saturation capacity. After inoculation with WSMV, plants were grown for approximately 4 weeks and then harvested. Root and shoot weights were measured to determine the effect of the disease on biomass. In all water treatments, root biomass and WUE of inoculated susceptible plants were significantly less $(P<0.05)$ than those of the noninoculated control plants. However, in the resistant cultivar, significance was only found in the 30 and $60 \%$ treatments for root weight and WUE, respectively. Field studies were also conducted under three water regimes based on reference evapotranspiration rates. Significant reductions in forage, grain yield, and crop WUE were observed in the inoculated susceptible plots compared with the noninoculated plots. Both studies demonstrated that wheat streak mosaic reduces WUE, which is a major concern in the Texas Panhandle because of limited availability of water.
\end{abstract}

The semi-arid High Plains states of Colorado, Kansas, Nebraska, New Mexico, Oklahoma, and Texas produced approximately 19,000,000 metric tons of wheat in 2007 , or $28.3 \%$ of the total U.S. wheat crop (1). Of the wheat grown in this region, approximately 1.0 million ha are supported by irrigation water from the Ogallala Aquifer (1). The Ogallala Aquifer underlies 45.1 million ha in the states of Colorado, Kansas, Nebraska, New Mexico, Oklahoma, South Dakota, Texas, and Wyoming (7). In all, $95 \%$ of the water pumped from the aquifer is used for irrigation of agricultural crops (12). Recharge of the aquifer, which totals only $11 \pm 2 \mathrm{~mm}$ year $^{-1}$, is insignificant when compared with the amount used for irrigation (17). Since the beginning of large-scale irrigation in the mid 1950s, total water storage in the aquifer has declined $311,190 \mathrm{hm}^{3}$ or $9 \%(12)$. As water use continues to exceed

\section{Corresponding author: C. M. Rush}

E-mail: cm-rush@tamu.edu

The mention of trade or manufacturer names is made for information only and does not imply an endorsement, recommendation, or exclusion by the United States Department of AgricultureAgricultural Research Service.

Accepted for publication 21 February 2010.

doi:10.1094/PDIS-94-6-0766

(C) 2010 The American Phytopathological Society recharge, the water level of the aquifer will continue to fall. For this reason, irrigation and crop water-use efficiency (WUE) have become important topics for research in areas dependant on the aquifer.

The majority of winter wheat in the High Plains is used as a dual-purpose crop, for both grazing and grain production, and is planted early in the season (late August and early September), so that sufficient biomass is available in the winter for cattle grazing. However, this creates an opportunity for a variety of insect pests and plant pathogens, by allowing early infestation and infection of the crop when temperatures are conducive. One of the most important wheat diseases throughout the High Plains region is wheat streak mosaic (WSM), caused by Wheat streak mosaic virus (WSMV), a member of the family Potyviridae (16). The virus is vectored by an eriophyid mite, the wheat curl mite, Aceria tosichella Keifer (15), which is disseminated by wind, thereby spreading the virus. Symptoms caused by WSMV include chlorosis, stunting, mosaic, and streaking. Yield losses of $50 \%$ or greater are common. In severe wheat streak years, producers routinely graze out an infected field because grain yields would not cover harvest expenses. Although the adverse effects on forage and grain yields have been recognized for years, little is known about the effects of the disease on plant root development and WUE. Due to the increasing depletion of ground water from the Ogallala Aquifer and the need to conserve this nonrenewable resource, a study was conducted to determine the effects of WSMV on root development and WUE of hard red winter wheat.

\section{MATERIALS AND METHODS}

Greenhouse studies. Greenhouse studies were conducted in January 2006 and February 2007 at the Texas AgriLife Research Center at Bushland, using susceptible (Karl 92) and resistant (KS96HW10-3, also known as KS 10-3) hard red winter wheat cultivars. The experiment was arranged in a randomized complete block design, containing six replications of cultivar-water level-inoculation treatments.

To establish water treatments, methods similar to those used by Piccinni and Rush (13), with minor modifications, were used. Plants were grown in PVC cylindrical pots, each containing $2 \mathrm{~kg}$ of a $1: 1$ mixture of field soil (Pullman clay loam and fine, mixed, superactive, thermic Torrertic Paleustoll) and fritted clay. The soil mixture in each pot was saturated with water for 3 days and then allowed to drain for 2 days to obtain weights at soil saturation. The saturation and dry weights of each pot were used to determine water content on a gravimetric basis. Based on the amount of water in each pot at saturation, three water treatments of 30,60 , and $80 \%$ soil saturation were established.

Approximately 8 to 10 seeds were planted in each pot and allowed to germinate. After germination, plants were thinned to four plants/pot, and each pot was considered an experimental unit. All pots were maintained at $60 \%$ soil saturation until inoculation, after which water treatments were initiated. Every 3 to 4 days, pot weights were recorded and water was added to reestablish pots to their predetermined percentage of soil saturation weight. The total amount of water used in each pot was determined at the end of the experiment.

At Feekes scale growth stage 3 (9), plants in half the pots were inoculated with WSMV and half were mock inoculated with inoculation buffer as WSMV negative controls. Inoculations were conducted using a $0.1 \mathrm{M}$ potassium phosphate inoculation buffer per WSMV mixture. Infected wheat leaves used for inoculum were collected the previous season and stored at $-20^{\circ} \mathrm{C}$ until inoculum preparation. The 
procedure used to inoculate wheat was similar to that described by Martin (11), with only minor modifications. Infected tissue was macerated in a blender with 1 liter of phosphate buffer (infected tissue at $40 \mathrm{~g} /$ liter $)$. Inoculum $(500 \mathrm{ml})$ plus $1 \mathrm{~g}$ of 600-grit Carborundum (silicon carbide powder), was sprayed at $0.41 \mathrm{MPa}$ on leaves using a spray paint gun. After approximately 12 days, infection was verified by double-antibody sandwich enzymelinked immunosorbent assay (DASELISA) using standard Agdia protocol and reagents (Elkhart, IN). However, polystyrene plates (Fisher Scientific, San Francisco) were used to reduce buffer and antibody serum from 100 to $50 \mu \mathrm{l}$. WSMV antiserum was used at a 1:200 ( $\mathrm{vol} / \mathrm{vol})$ dilution. Tissue was ground at a ratio of 1 $\mathrm{g}$ per $10 \mathrm{ml}$ of extraction buffer. Individual sample wells were evaluated by absorbance at $405 \mathrm{~nm}$ using an Emax precision microplate reader (Molecular Devices Corp., Union City, CA). Tissues from noninoculated plants served as controls.

After approximately 12 weeks, plants were harvested, and roots and shoots were separated just above the crown and dried in an oven at $60^{\circ} \mathrm{C}$ for 5 days. Roots and shoots were weighed, and WUE (grams of total dry biomass per liters of total water used) for each cultivar-disease-water treatment unit was determined.

Field studies. Field studies were conducted at the Texas AgriLife Research Farm, Bushland, during the 2006 and 2007 winter-wheat seasons. The field site consisted of 14 ha under a 294-m center-pivot irrigation system. The pivot system was composed of six 49-m spans, each containing 36 midlevel drops with sprinkler nozzles. Each drop was equipped with an on/off valve, which allowed for establishment of randomized water treatments. Treatments were arranged in a randomized split-plot design, with water treatment as the main plot and cultivar-inoculation as the subplot. Wheat for this study was planted on a 2.4-ha wedge of the irrigated field. The wedge was divided into $12 \mathrm{sec}-$ tions representing four replications of each of the three main water treatments. Each cultivar-inoculation combination was treated as a separate treatment and randomized within each water treatment.

Three water treatments (Table 1) were designed using estimates of water use for wheat obtained from the Texas High Plains Evapotranspiration Network (10). Treatment 1 was managed as a dryland treatment and did not receive any irrigation water. Treatment 2 received half the water applied to treatment 3 , which received $67 \%$ of estimated water use for wheat.

Soil volumetric water content was determined using a neutron probe (model 503DR1.5; CPN Corp., Concord, CA), calibrated for use in a Pullman clay loam soil (5). The probe was introduced through 3.8-cm-diameter electromechanical access tubes, $3 \mathrm{~m}$ in length. Access tubes were inserted with a Giddings hydraulic soil coring unit (Giddings Machine Co., Fort Collins, CO), mounted on a tractor, to a depth of approximately $2.85 \mathrm{~m}$, into four subplots in each main water treatment: two subplots planted with Karl 92, one inoculated and one noninoculated, and two subplots planted with KS 10-3, one inoculated and one noninoculated. These plots were randomly selected within each of the main water treatments. Measurements were taken at increments of $0.2 \mathrm{~m}$ to a depth of $1.3 \mathrm{~m}$ once a month from October to May. Profile water content was determined by integrating the soil water content values from the soil surface to the underlying caliche layer, below which differences were found to be negligible. Water content was used to show differences in the amount of water removed from the soil profile by inoculated and noninoculated plants of both cultivars, grown under all water treatments.

Plots were planted to wheat at a seed rate of $67.2 \mathrm{~kg} \mathrm{ha}^{-1}$ during the first week of September. Within each irrigation main plot, four (3-by-3-m) subplots of KS 10-3 and Karl 92 were planted. Bulk wheat (cv. TAM 105) was planted around the plots to simulate more normal field conditions. The field was fertilized with nitrogen at $53.4 \mathrm{~kg}$ $\mathrm{ha}^{-1}$, applied through the center pivot.

Half the plots of each cultivar were inoculated during the first week of October and again 3 weeks later, as previously described for greenhouse inoculations. Noninoculated plots of each cultivar served as WSMV-negative controls. The presence of viral infection was verified by DAS-ELISA, as previously described for the greenhouse study.

Aboveground biomass was collected in April from all plots by cutting a $10.2-\mathrm{cm}$ section from each of four rows. Plants were cut above the crown, and tissue collected from each of the four rows was bulked and dried in a forced-air drying room at $40^{\circ} \mathrm{C}$ to obtain dry biomass weights from each plot. Plots were harvested in the last week of June and grain yield weights were determined. Crop WUEs for aboveground biomass and grain yield were determined by dividing dry biomass and grain yield by total volume of irrigation water applied plus precipitation (in grams per millimeter; Table 1). WUE for nonirrigated treatments was determined by using the amount of precipitation throughout the season. Total water (irrigation and rainfall) up to the day of biomass collection was used to calculate WUE for aboveground biomass. Irrigation was measured using a meter on the center-pivot irrigation system, and precipitation was measured in a nearby rain gauge.

Data analysis. Before analysis, data were transformed using log transformation to make the variances homogenous. The greenhouse data were analyzed using
PROC MIXED (SAS Institute Inc, Cary, $\mathrm{NC}$ ), in which the treatments served as fixed effects and blocks as random effects. Pairwise comparisons of treatment means were conducted using LSMEANS with the DIFF option. Data from the field study were analyzed using PROC GLM, in which differences among irrigation levels were tested using the interaction between water and block as the error term. Inoculation treatments were tested using the pooled error term and treatment means were separated using the Waller-Duncan multiple-range test.

\section{RESULTS}

Greenhouse studies. Initial analysis indicated that there was no significant interaction between the 2006 and 2007 data for inoculation treatments $(P>0.05)$. Therefore, data were averaged across years and analyzed. There were highly significant differences among each of the water, cultivar, and inoculation treatments for root weight (Table 2). Two-way interactions between the treatments also were highly significant. In the susceptible cultivar (Karl 92), root weights of inoculated wheat plants were significantly lower than those of noninoculated plants in all water treatments $(P<0.05$; Fig. 1A). In the resistant cultivar (K10-3), differences in root weights between inoculated and noninoculated plants were not significant in the 80 and $60 \%$ water treatments $(P>0.05)$ but were significant in the $30 \%$ water treatment, in which noninoculated plants showed greater root weight than inoculated plants $(P=0.0171)$.

The effect of water treatments on root weight was mixed. The root weights of inoculated, susceptible plants at $60 \%$ soil saturation were significantly greater than those in the 30 and $80 \%$ water treatments but there was no significant difference between the 30 and $80 \%$ saturation (Fig. 1A). However, unlike those of inoculated plants, root weights of the noninoculated plants increased with increasing soil saturation and the differences were highly significant $(P<0.05)$. Root weights increased with increasing soil saturation in both inoculated and noninoculated plants in the resistant cultivar as well $(P<0.05$; Fig. 1A).

Table 1. Irrigation treatments used in the 2006 field study at the Texas AgriLife Research Station (Bushland, TX) and the corresponding amounts of irrigation water applied (Irrig), precipitation (Precip), and total water

\begin{tabular}{lccc}
\hline $\begin{array}{l}\text { ET } \\
(\%)^{\mathbf{a}}\end{array}$ & $\begin{array}{c}\text { Irrig } \\
(\mathbf{m m})\end{array}$ & $\begin{array}{c}\text { Precip } \\
(\mathbf{m m})\end{array}$ & $\begin{array}{c}\text { Total } \\
(\mathbf{m m})\end{array}$ \\
\hline 0 & 0 & 63.8 & 63.8 \\
33 & 243.8 & 63.8 & 307.6 \\
67 & 487.7 & 63.8 & 551.5 \\
\hline
\end{tabular}

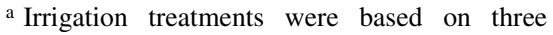
levels of estimated reference evapotranspiration (ET). 
Response of shoot biomass to individual treatments was similar to that of root weight in that the treatments were highly significant; also, there was a significant cultivar-inoculation interaction (Table 2). However, unlike those in root weight, interactions between water and cultivar and water and inoculation treatments were not significant (Table 2). Shoot biomass of the inoculated, susceptible cultivar was significantly lower than those of noninoculated plants at 80 and $60 \%$ soil saturation but not at $30 \%$. However, in the resistant cultivar, there were no significant differences between inoculated and noninoculated plants at all soil saturation treatments $(P>0.05$; Fig. 1B). Unlike the root weight, shoot biomass significantly increased with increasing water saturation in all inoculations $(P<0.05)$.

Each of the three treatment variables (water, inoculation, and cultivar) were highly significant for WUE (for root weight and shoot biomass) and also, as in root weight, all of the two-way interactions were highly significant (Table 2). In the susceptible cultivar, inoculated plants had significantly lower WUEs than the noninoculated plants at all soil saturation treatments $(P<0.05$; Fig. $1 C)$. However, in the resistant cultivar, WUE was not significantly different between inoculated and noninoculated plants $(P>0.05)$ except at the $60 \%$ water treatment $(P=$ 0.0113).

Field studies. The 2006 season was a drought year and, consequently, there were dramatic differences among irrigation treatments. However, in 2007, near-record rainfall significantly reduced the effects of irrigation treatments. In addition, inoculations were not as successful in establishing adequate disease levels as in 2006 , resulting in minimal disease incidence and severity. Therefore, only results of the 2006 study are presented.

Highly significant differences were observed among water treatments for all measured variables (aboveground biomass, yield, and WUEs; Table 3). Inoculation treatments also were highly significant for all the variables. However, interactions between water and inoculation treatments were not significant (Table 3). Therefore, differences among inoculation treatments were determined using means inclusive of
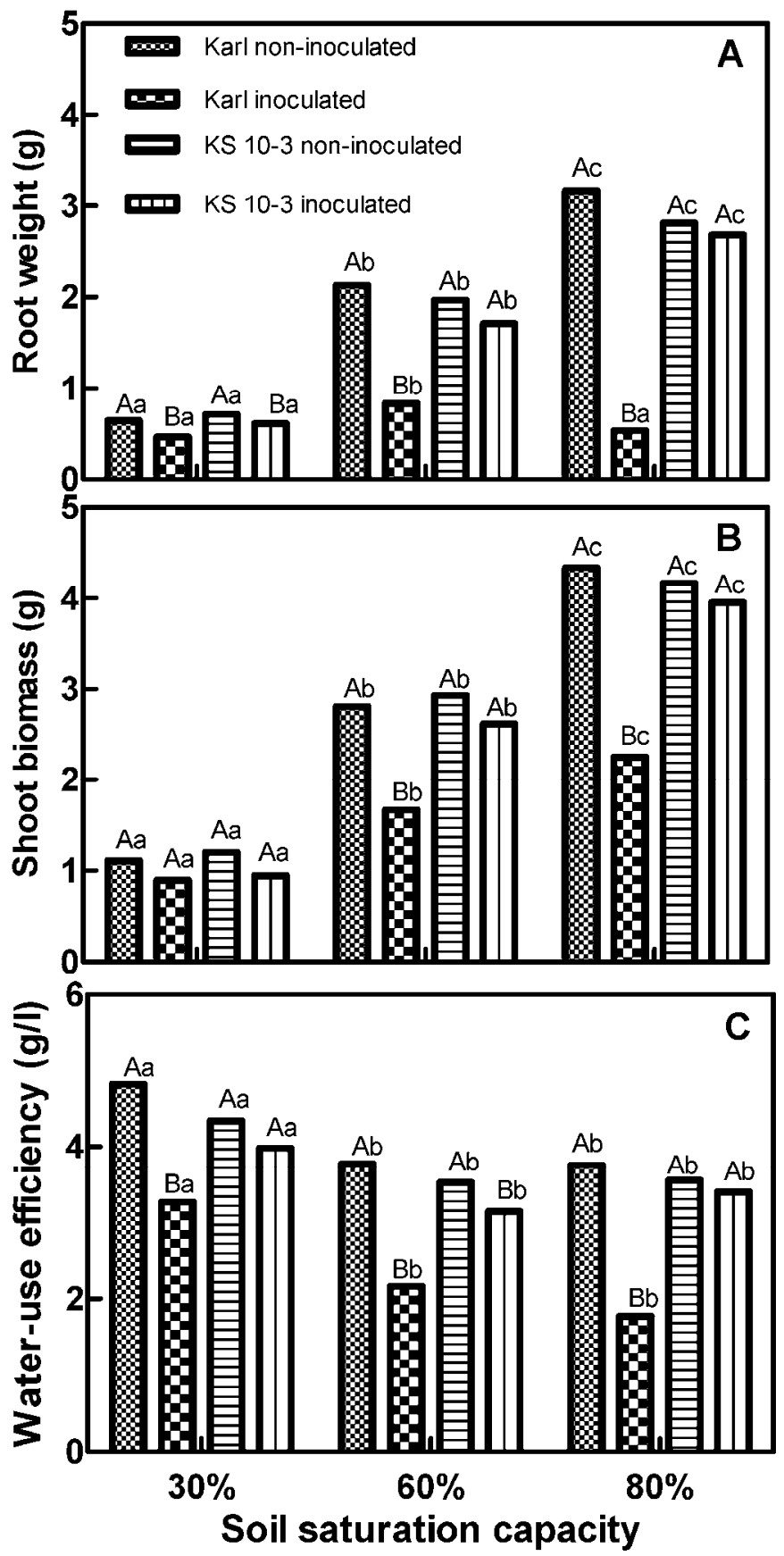

Fig. 1. Effects of inoculation with Wheat streak mosaic virus in the greenhouse of susceptible (Karl 92) and resistant (KS10-3) wheat cultivars on A, root weight; B, shoot biomass; and $\mathbf{C}$, water-use efficiency at three soil-saturation capacities $(30,60$, and $80 \%)$. Bars within a cultivar and water treatment labeled with the same uppercase letter are not significantly different by tests of least square means differences $(P>0.05)$. Bars representing the same cultivar and inoculation treatment across water treatments labeled with the same lowercase letter are not significantly different by tests of least square means differences $(P>0.05)$.

Table 2. Statistical tests for the main effects and interactions of water level, wheat cultivar, and inoculation with Wheat streak mosaic virus on root weight, shoot biomass, and water-use efficiency (WUE) across two experiments in the greenhouse

\begin{tabular}{|c|c|c|c|c|c|c|c|}
\hline \multirow[b]{2}{*}{ Source } & \multirow[b]{2}{*}{ df } & \multicolumn{2}{|c|}{ Root weight } & \multicolumn{2}{|c|}{ Shoot biomass } & \multicolumn{2}{|c|}{$\mathbf{W U E}^{\mathbf{a}}$} \\
\hline & & $F$ & $P>F$ & $F$ & $P>F$ & $\boldsymbol{F}$ & $P>F$ \\
\hline Water & 2 & 142.47 & $<0.0001$ & 267.20 & $<0.0001$ & 44.85 & $<0.0001$ \\
\hline Cultivar (cult) & 1 & 51.06 & $<0.0001$ & 24.39 & $<0.0001$ & 42.02 & $<0.0001$ \\
\hline Water $\times$ cult & 2 & 10.48 & 0.0001 & 1.93 & 0.1548 & 5.84 & 0.0051 \\
\hline Inoculation (inoc) & 1 & 91.62 & $<0.0001$ & 35.68 & $<0.0001$ & 121.86 & $<0.0001$ \\
\hline Water $\times$ inoc & 2 & 10.10 & 0.0002 & 0.65 & 0.5244 & 3.81 & 0.0285 \\
\hline Cult $\times$ inoc & 1 & 44.87 & $<0.0001$ & 14.66 & 0.0003 & 93.23 & $<0.0001$ \\
\hline Water $\times$ cult $\times$ inoc & 2 & 16.52 & $<0.0001$ & 2.77 & 0.0713 & 0.96 & 0.3900 \\
\hline
\end{tabular}

a WUE was calculated by dividing shoot biomass by total water added (grams per liter). 
all water treatments. In the susceptible cultivar, mean aboveground biomass, grain yield, and WUEs for biomass and grain yield were significantly greater in noninoculated than in inoculated plots $(P<$ 0.05 ; Fig. 2A-D, respectively). However, in the resistant cultivar, differences between inoculated and noninoculated plots for the above variables were not significant $(P>0.05$; Fig. 2A-D). Overall, the resistant cultivar had significantly greater biomass, grain yield, and WUEs than the susceptible cultivar.

The soil water content in plots planted to Karl 92 and inoculated with WSMV remained consistently greater (but not significant at $P=0.05$ ) throughout the soil profile $(0$ to $110 \mathrm{~cm})$ than in plots containing noninoculated Karl 92 (Fig. 3). In addition, throughout the soil profile, soil water content was lower for plots containing inoculated and noninoculated K10-3 than in plots planted to the susceptible cultivar and inoculated with WSMV.

\section{DISCUSSION}

Crop WUE is a major concern in the Texas Panhandle because of the limited water resource. To our knowledge, this is the first study to demonstrate that WSM can be a significant contributing factor to WUE in the region. The greenhouse studies showed that the disease drastically affects plant (root and shoot) biomass and WUE. Similar results were observed in the field study, in which inoculated Karl 92 showed a decrease in aboveground biomass and grain yield compared with the noninoculated control. The decrease in root weight and WUE observed in the greenhouse experiments, along with the higher soil water content observed in the field study, suggest that the reduction in root growth observed in the greenhouse study also occurred in the field study. A reduction in root growth of plants in inoculated field plots would help explain the greater soil water content measured in inoculated plots. These results were confirmed in experiments conducted in grower's fields, in which WSM severity was strongly negatively correlated with grain yield and WUE but positively correlated with soil moisture content $(18,19)$.

Studies have shown that, with an increase in rooting depth and density, there is a concomitant increase in water uptake (2). It also has been shown that increasing root biomass in spring wheat, using a wheat-rye translocation, contributed to an increase in crop and plant WUE (4) as well as greater shoot biomass and grain yield $(3,8)$. However, when disease enters the system, grain yield, plant biomass, and WUE are severely reduced $(13,19)$, as shown in the current greenhouse and field studies.

Table 3. Statistical tests for the main effects of soil water level, treatments consisting of two wheat cultivars with and without inoculation with Wheat streak mosaic virus and their interactions on aboveground biomass, yield, and water-use efficiency (WUE) ${ }^{\mathrm{a}}$ in a field study at Bushland, TX in 2006

\begin{tabular}{|c|c|c|c|c|c|c|c|c|c|}
\hline \multirow[b]{2}{*}{ Source } & \multirow[b]{2}{*}{ df } & \multicolumn{2}{|c|}{ Biomass } & \multicolumn{2}{|c|}{ WUE biomass } & \multicolumn{2}{|c|}{ Yield } & \multicolumn{2}{|c|}{ WUE yield } \\
\hline & & $F$ & $P>F$ & $\boldsymbol{F}$ & $P>F$ & $\boldsymbol{F}$ & $P>F$ & $\boldsymbol{F}$ & $P>F$ \\
\hline Block & 3 & 2.85 & 0.0475 & 2.85 & 0.0475 & 3.13 & 0.0354 & 3.25 & 0.0310 \\
\hline Water & 2 & 22.47 & 0.0016 & 77.25 & $<0.0001$ & 50.14 & 0.0002 & 24.15 & 0.0013 \\
\hline Block $\times$ water & 6 & 2.31 & 0.0488 & 2.31 & 0.0488 & 1.41 & 0.2341 & 1.65 & 0.1565 \\
\hline Treatment (trt) & 3 & 75.38 & $<0.0001$ & 75.98 & $<0.0001$ & 102.29 & $<0.0001$ & 114.29 & $<0.0001$ \\
\hline Block $\times$ trt & 9 & 1.59 & 0.1703 & 1.59 & 0.1450 & 2.07 & 0.0542 & 2.44 & 0.0246 \\
\hline Water $\times$ trt & 6 & 1.59 & 0.1703 & 1.59 & 0.1703 & 0.64 & 0.6980 & 0.47 & 0.8296 \\
\hline Block $\times$ water $\times$ trt & 18 & 1.33 & 0.2180 & 1.33 & 0.2180 & 1.17 & 0.3275 & 1.46 & 0.1540 \\
\hline
\end{tabular}

${ }^{a}$ WUE was calculated by dividing biomass and grain yield by total volume of water applied plus precipitation (grams per millimeter).
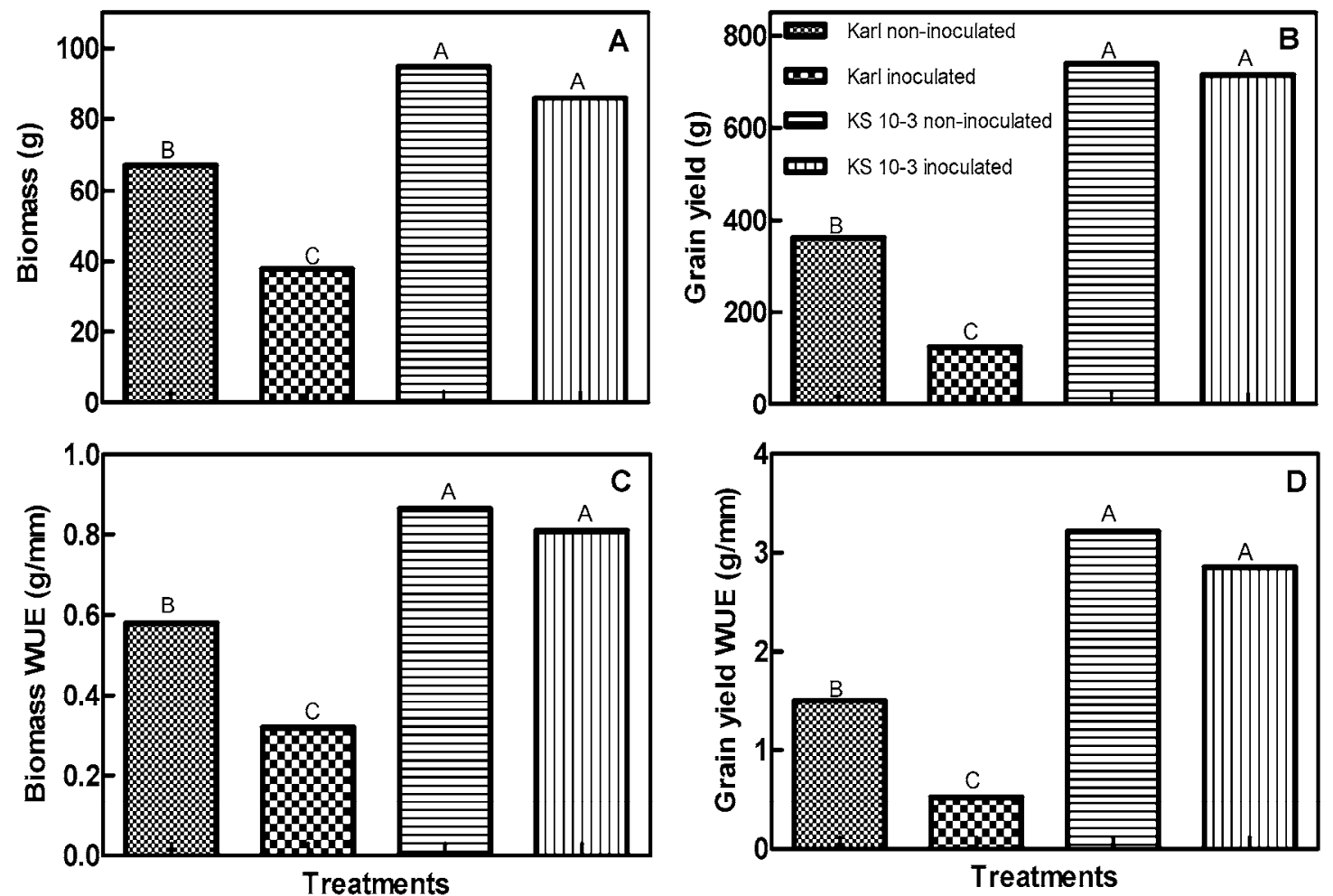

Fig. 2. Effects of field inoculation of susceptible (Karl 92) and resistant (KS 10-3) wheat cultivars on A, aboveground biomass; B, grain yield; and water-use efficiencies (WUEs) for C, aboveground biomass and D, grain yield in a study conducted at Bushland, TX in 2006 . Each bar represents a mean of three water treatments shown in Table 1 . Bars labeled with the same letter are not significantly different $(P>0.05)$ according to Waller-Duncan multiple range tests. 
Volumetric soil water $(\mathrm{mm})$

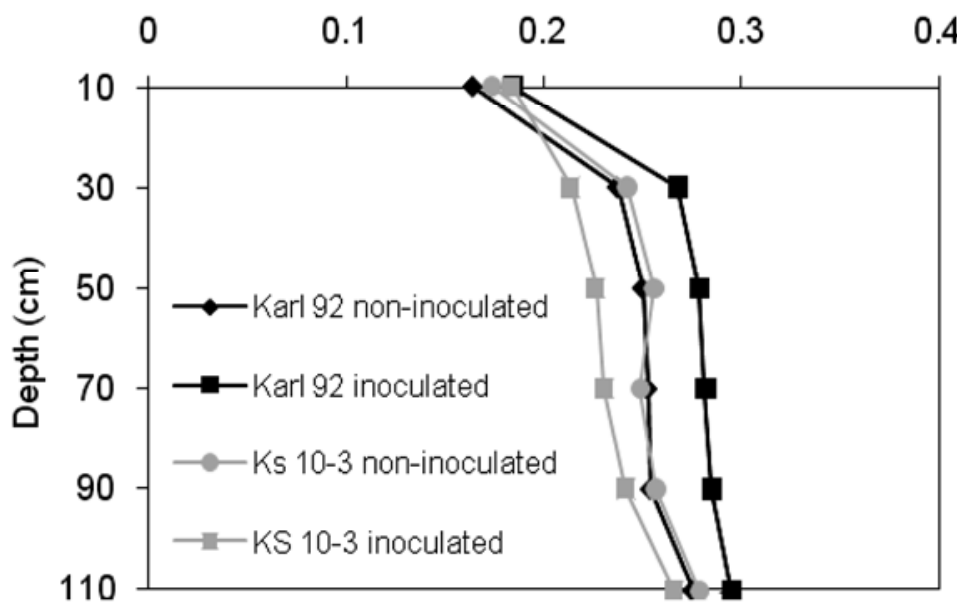

Fig. 3. Effects of wheat streak mosaic on soil water content for the $67 \%$ evapotranspiration reference collected on 18 April 2006 at the Texas AgriLife Research Station (Bushland, TX), in plots of inoculated and noninoculated Karl 92 (susceptible) and KS10-3 (resistant) wheat cultivars.

Under conditions of low or no WSM pressure, Karl 92 and K10-3 have similar yield potential (14). However, there was a natural infection late in the spring of 2006 which affected the yield of noninoculated Karl 92 more than the resistant cv. K10-3. Because fall infections generally cause greater damage than spring infections (6), the fall-inoculated Karl 92 plots still had significantly lower grain yield than the noninoculated control plots, which were naturally infected later in the spring.

A significant increase in aboveground biomass and grain yield was observed with an increase in the amount of water applied with the susceptible, noninoculated Karl 92 and the resistant KS 10-3 (inoculated or noninoculated). However, no significant increase was observed in biomass and grain yield in Karl 92 inoculated with WSMV. This suggests that, in infected fields, application of water doesn't significantly increase plant growth or grain yield. However, more research needs to be conducted to determine the relationships among time of infection, disease severity, irrigation management, and WUE.

The combined findings of the greenhouse and field studies demonstrate that fall infection of susceptible wheat cultivars with WSMV not only reduces forage and grain yields but also root development, which leads to reduced WUE (4). Root development and WUE are highly important in wheat production under conditions that depend on efficient use of moisture and these findings demonstrate that, once infection occurs, an increase in water application does not increase plant growth or grain yield.
In a study conducted by Piccinni and Rush (13), infection of sugar beet with Beet necrotic yellow vein virus resulted in a reduction in water uptake and WUE. Other than this, minimal research has been conducted to determine the effects of disease, especially viral diseases, on WUE of wheat or any other crop. Thus, the present study is of particular importance for wheat producers in the High Plains region. This area is responsible for $28 \%$ of wheat production in the United States and is particularly dependent on irrigation to maintain high production. With increasing energy prices and the need to conserve ground water, studies to determine the effects of disease on WUE are of great importance. This study demonstrated that WSMV had a highly significant effect on root growth, water uptake, and WUE, which highlights the need for development of resistant cultivars. Furthermore, given the fact that wheat streak, in many cases, is a progressive disease that often begins on the edges of fields (19), there is potential for improving overall crop WUE in the field by using site-specific irrigation.

\section{ACKNOWLEDGMENTS}

This research was supported in part by the Ogallala Aquifer Initiative, a consortium between the United States Department of AgricultureAgricultural Research Service, Kansas State University, Texas AgriLife Research, Texas AgriLife Extension Service, Texas Tech University, and West Texas A\&M University. The project was also partially supported by the Texas Cropping Systems Initiative and the Texas Wheat Producers Board.

\section{LITERATURE CITED}

1. Anonymous. 2008. Crop Production 2007 Summary. National Agricultural Statistics Service. United States Department of Agriculture. Jan. 2008. Cr Pr 2-1 (08).
2. Dugas, W., Upchurch, D., and Ritchie, J. 1985. A weighing lysimeter for evapotranspiration and root measurements. Agron. J. 77:821-825.

3. Ehdaie, B. 1995. Variation in water-use efficiency and its components in wheat 2. pot and field experiments. Crop Sci. 35:1617-1626.

4. Ehdaie, B., Whitkus, R., and Waines, J. 2003. Root biomass, water-use efficiency, and performance of wheat-rye translocation of chromosomes 1 and 2 in spring bread wheat "Pavon". Crop Sci. 43:710-717.

5. Evett, S. R. 2008. Neutron moisture meters. Pages 39-54 in: Field Estimation of Soil Water Content: A Practical Guide to Methods, Instrumentation, and Sensor Technology. S. R. Evett, L. K. Heng, P. Moutonnet, and M. L. Nguyen eds. IAEA, TCS-30, Vienna.

6. Hunger, R., Sherwood, J., Evans, C., and Montana, J. 1992. Effects of planting date and inoculation date on severity of wheat streak mosaic in hard red winter wheat cultivars. Plant Dis. 76:1056-1060.

7. Jensen, R. 2003. Groundwater in the Great Plains. Report 141. Texas Water Resources Institute at Texas A\&M University and Great Plains Agricultural Council.

8. Klepper B., Belford, R., and Rickman, R. 1984. Root and shoot development in winter wheat. Agron. J. 76:117-122.

9. Large, E. 1954. Growth stages in cereals: Illustration of the Feeke's scale. Plant Pathol. 3:128-129.

10. Marek, T. H., Dusek, D., New, L. L., Fipps, G., Howell, T. A., and Sweeten J. 1998. Potential evapotranpiration networks in Texas: design, coverage and operation. Pages 115-124 in: Proc. 25th Water Texas Conf. Austin, TX.

11. Martin, J. T. 1978. Procedures for evaluating Wheat streak mosaic virus resistance. Plant Dis. Rep. 62:1062-1066.

12. McGuire, V. L. 2006. Water-level changes in the High Plains aquifer, predevelopment to 2005 and 2003 to 2005. U.S. USGS Scientific Investigation Report 2006-5324.

13. Piccinni, G., and Rush, C. M. 2000. Determination of optimum irrigation regime and wateruse efficiency of sugar beet grown in pathogen-infested soil. Plant Dis. 84:1067-1072.

14. Seifers, D. L., Martin, T. J., Harvey, T. L., Haber, S., and Haley, S. D. 2006. Temperature sensitivity and efficacy of Wheat streak mosaic virus resistance derived from CO960293 wheat. Plant Dis. 90:623-628.

15. Slykhuis, J. T. 1955. Aceria tulipae Keifer (Acarina: Eriophyidae) in relation to the spread of wheat streak mosaic. Phytopathology 45:116-128.

16. Stenger, D., Hall, J., Choi, I., and French, R. 1998. Phylogenetic relationships within the family Potyviridae: Wheat streak mosaic virus and Brome streak mosaic virus are not members of the genus Rymovirus. Phytopathology 88:782-787.

17. Wood, W., and Sanford, W. 1995. Chemical and isotopic methods for quantifying groundwater recharge in a regional, semiarid environment. Ground Water 33:458-468.

18. Workneh, F., Jones, D. C., and Rush, C. M. 2009. Quantifying wheat yield across the field as a function of wheat streak mosaic intensity: a state space approach. Phytopathology 99:432-440.

19. Workneh, F., Price, J. A., Jones, D. C., and Rush, C. M. 2010. Wheat streak mosaic: A classic case of plant disease impact on soil water content and crop water-use efficiency. Plant Dis. 94:771-774. 